\title{
Baby longing and men's reproductive motivation
}

\author{
Anna Rotkirch, Stuart Basten, Heini Väisänen and Markus Jokela*
}

\begin{abstract}
Childbearing in low-fertility societies sometimes results from a strong desire to have a(nother) child. Since women tend to dominate discussions on 'baby longing' or 'baby fever', it is not clear whether men also feel the powerful urge to have a child. Moreover, the demographic importance of baby longing has yet to be assessed. Using cross-sectional surveys from contemporary Finland and focusing on men, we analyse gender differences in baby longing.

Both sexes report having felt an intense longing to have a child of their own at least once or a few times in their lives. A higher proportion of men say they have never longed for a child, while a higher proportion of women report having felt this longing frequently. Baby longing figures at different stages of the TraitsDesires-Intentions-Behaviour scheme of reproductive behaviour. For a small minority of men, longing first appears in youth. Baby longing among men most commonly plays into childbearing desires preceding attempts to achieve pregnancy. However, about every third man reports having first felt this longing only when trying to have a child. Baby longing among men is unrelated to economic and educational status, but it is associated with marital status, fertility intentions and the number of lifetime unions. Compared to its effects on women, baby longing among men is reported to result in having a child less often and to have less influence on childbearing decisions. We conclude that women's longing shapes the couple's fertility behaviour to a slightly higher degree than men's longing does, especially with regards to higher parities. Men's baby longing may be especially important for sustaining proceptive behaviour and preparing for fatherhood.
\end{abstract}

\footnotetext{
* Anna Rotkirch (correspondence author), Population Research Institute, Väestöliitto, POB 849, FIN-00101 Helsinki, Finland. Email: anna.rotkirch@vaestoliitto.fi

Stuart Basten: Oxford Centre for Population Research, Department of Social Policy and Intervention, University of Oxford, Great Britain.

Heini Väisänen: Department of Sociology, University of Helsinki, Finland.

Markus Jokela: Department of Psychology, University of Helsinki, Finland.
}

DOI: 10.1553/populationyearbook2011s283 


\section{Introduction}

Childbearing in contemporary low-fertility societies typically results from a deliberate decision by the woman or the couple to have a child. The spread of modern contraception and reproductive rights has shifted the emphasis from contraception to conception, and from 'unwanted' to 'mistimed'. Individuals become sexually mature earlier but postpone starting reproduction to their late twenties, which provides them with more years to ponder childbearing, and to experience both ambivalence about and longing for children.

Personal conversations, media coverage and online discussions about 'baby fever' and 'baby lust' - or, more dramatically, 'baby angst' and 'baby hunger' have spread in recent decades (Rotkirch 2007, 2008; Mills 2010; Pikul 2011). Within these conversations on blogs, chat rooms and online forums, women are usually both the facilitators and discussants (see, for example, confessionsofameanmommy.com 2009). Men's experiences of baby longing are articulated less frequently. But, as the journalist David Mills (2010) asked while reflecting on his own experience, "Why can't men be broody too? Women aren't the only ones with biological clocks. The difference is that they can talk about it". Up to now, however, there have been no studies on how baby longing differs between the sexes and between different men.

Demographic research on men's attitudes and approaches to fertility has blossomed after a long period of relative neglect (e.g. Thomson 1997; Thomson et al. 1990; Booth and Crouter 1998; Forste 2002; Puur et al. 2008; Jamieson et al. 2010, p.482). Socio-economic, union, and individual factors have all been shown to affect male fertility (de Bruijn 1999; von der Lippe 2010). Within couples in developed societies, men and women have been shown to have broadly similar fertility intentions at most ages and stages of family building, with relatively little disagreement (Thomson 1997; Thomson and Hoem 1998; Miller and Pasta 1995). Some results have, however, indicated that women are more often the 'driving force' in shaping fertility intentions, while men exhibit more drift and less momentum in family formation (Berrington 2004; Henwood 2009; Roberts et al. 2011).

We study men's baby longing using survey data from contemporary Finland, exploring socio-demographic and gender differences in baby longing and its behavioural outcomes. Of special interest to us is the goal of situating baby longing within the Traits-Desires-Intentions-Behaviour theory of reproductive behaviour (Miller 1986, 1992; Miller and Pasta 1995). Qualitative data from an ongoing study is also used for illustrative purposes. The article is structured as follows. After a theoretical discussion of baby longing and the role of parenting emotions in fertility behaviour, followed by a presentation of our data and methods, we first analyse gender differences in reported experiences of baby longing and its effect on childbearing in the adult Finnish population. We then seek to identify which social, demographic and other factors have associations 
with baby longing in a study of zero- and one-parity adults in Finland. The focus is on men, but comparable data for women are provided in order to determine which aspects characterise male baby longing, and which are shared by both sexes.

\section{Analytical framework}

Among the many factors affecting fertility outcomes, we may distinguish between two main mechanisms: on the one hand, social stratification and mate selection and on the other hand, motivated individual reproductive behaviour (von der Lippe 2010, see also de Bruijn 1999; Trivers 1972). Individual fertility motivation can in turn be divided into two distinct motive systems: desires and intentions (Miller 2011).

In most societies, men's but not women's fertility is related to social status. For example, the number of children men have correlates positively with income and education in the USA (Hopcroft 2006); and with the level of education in Germany, Norway and Finland (von der Lippe 2010; Kravdal and Rindfuss 2008; Population Research Institute 2010).

This effect of social status on male fertility is driven by a higher risk of childlessness among low-status men, probably due to mate choice preferences (Nettle and Pollett 2008). Having many sexual partners and marriages is related to higher fertility for men but not for women, at least in the USA (Hopcroft 2006; Jokela et al. 2010). Men with higher levels of education also spend more time with their children (Kaplan et al. 1998), including more active 'development' time (Nettle 2008; Bonke and Esping-Andersen 2009). However, research on fatherhood, fathering styles and child development often omits men's fertility motivations (e.g. Lamb 2010). For instance, we know little about whether the higher fertility of men with high socio-economic status or with several unions is preceded by an emotional orientation towards fatherhood, or whether it instead results from partner and lifestyle effects. Here, we approach this broad question by examining one particular emotion: baby longing.

Humans and many other primates exhibit considerable variation in parenting emotions, both between the sexes and between individuals (Maestripieri 1999 2011; Miller 2001; Fernandez-Duque et al. 2009; Nettle 2011). For instance, attraction to infants varies between males and females, but also according to an individual's age and the ages of his or her offspring (Maestripieri et al. 2004; Silk 2003). Among species in which the fathers provide extensive amounts of care, paternal emotions appear to be both partly overlapping with and partly distinct from maternal emotions. Recent studies in humans suggest that mothers and fathers share neuroendocrine pathways, but they also show that the same emotion (e.g. bonding with an infant) may be triggered by different behaviours, such as 
affectual interaction or exploratory play with the infant (Fleming et al. 2002; Gordon et al. 2010a, 2010b).

In the demographic literature, Warren B. Miller's research on reproductive behaviour represents the most comprehensive attempt to integrate emotions into the study of childbearing motivations. The Traits-Desires-Intentions-Behaviour (TDIB) scheme developed by Miller and colleagues depicts a progression from general traits to childbearing desires, which in turn influence fertility intentions and behaviour, and finally lead to childbearing outcomes (Miller 1986; Miller and Pasta 1995; Miller et al. 2010; Miller in this issue, see Figure 1 below). Traits represent an individual's motivational basis, or a general disposition vis-à-vis childbearing which develops by gene-environment interactions during childhood. Desire is defined as synonymous with wishes and wants, while intentions relate to actual plans. The distinction between desire and intentions resembles the differentiation between ideals and intentions that has been made in many fertility studies (e.g. Thomson 1997). Desire is, therefore, not defined in its alternative meaning of craving, yearning and desperate need; although desires, wishes and wants may of course encompass deep longing. The TDIB scheme further separates childbearing desires and intentions into the desire or intention to have a child, to have a specific number of children and to have them at a particular time; as well as the perceptions and influences of the partner desire's on the individual's fertility intentions (Miller et al. 2004).

Baby longing or 'baby fever' is a visceral emotional and physical desire to have a baby, and it is one of the emotions affecting reproductive behaviour and parenting (Rotkirch 2007; Brase and Brase 2011). We define baby longing as a powerful longing to have a child of one's own; that is, a childbearing desire in the stronger sense of the word. Previous research has shown that, in women's experiences, baby longing can be both psychological (dreams, obsessive thoughts and plans, attraction to infants and baby merchandise) and physical (a tug in the womb, a tension in the breasts, an aching stomach) (Rotkirch 2007). Baby longing been described by some individuals as a constant feeling that began in early adulthood, which situates it among the basic motivational traits in the TDIB scheme. For other people, this urge may appear as a surprise at later life stages, and may thus interact with the latter phases of the TDIB scheme in various ways. A recent psychological study found that baby fever was not explained by sex role socialisation or the need to nurture, and that it was inversely related to the strength of the sexual drive. It was most frequent among women in their twenties (Brase and Brase 2011).

The TDIB scheme stresses that reproductive behaviour is both contraceptive and proceptive; in order to have a child 'at the right time', people must not have children at other times. This is in line with the biological view of parental investment, defined as the channelling of resources to one offspring to the detriment of other (existing or future) offspring (Trivers 1972). The ultimate causes and proximate psychological mechanisms of baby longing are as yet 
unclear, although existing evidence suggests it may have evolved as an emotional mechanism for facilitating reproductive timing and the shift from the mating to the parenting effort (Rotkirch 2007; Brase and Brase 2011; Miller in this issue). In this case, baby longing signals when it might be 'a good time' to have a child in relation to the individual's age and condition, romantic partners, and existing and expected social and material resources. For a childless woman or a couple, baby longing may improve parenting motivation, lead to the development of parenting skills through increased interactions with other people's infants and prepare the woman or couple emotionally for adoption. There is also a difference between baby longing in the form of the first joyful and tentative thoughts of a possible child, and baby longing as the deep sorrow resulting from unsuccessful attempts to have a child. These aspects remain outside the scope of this study.

Figure 1 depicts some plausible places for baby longing on the TDIB scheme.

Figure 1:

Different possible instances of baby longing in the TDIB scheme (outer circle adapted from Miller et al. 2010)

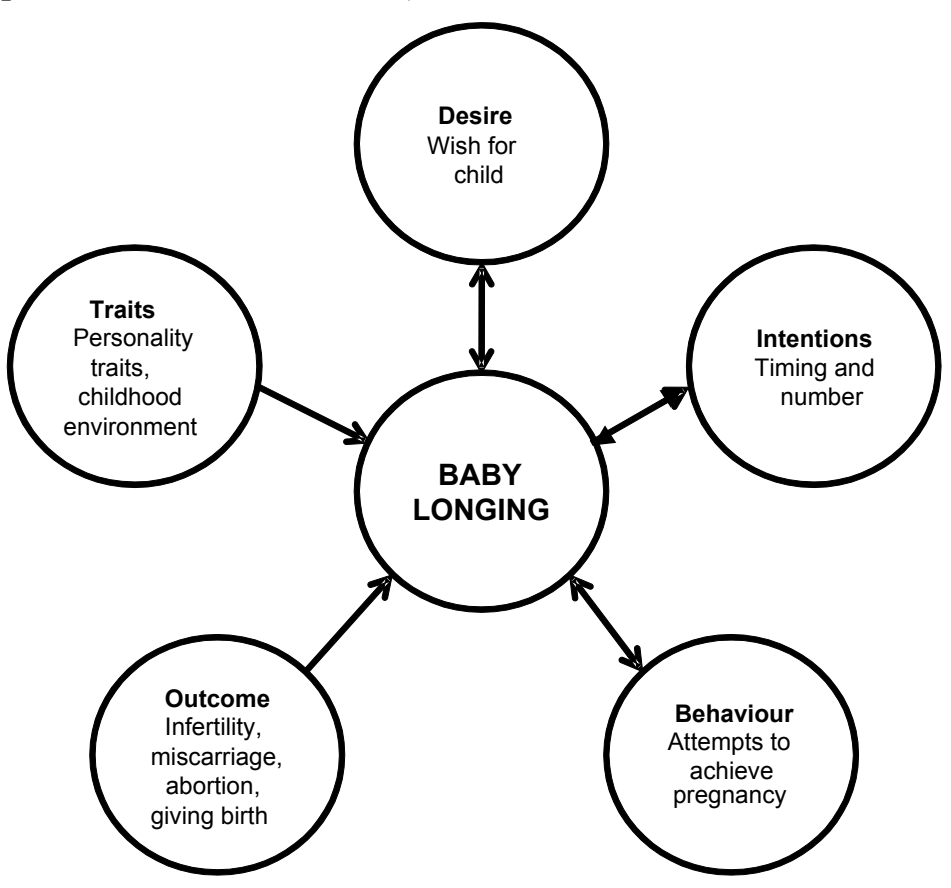

Starting from the top-left circle, we can see that the traits underlying childbearing motivations include personality traits (such as agreeableness and nurturance) and childhood experiences (growing up with many siblings or other exposure to infants), which can develop into a longing for babies. This longing is 
a component of the individual's general and long-term motivation to have children.

Second, the effect of baby longing on fertility desires and intentions goes both ways: longing may trigger and intensify the wish or plan to have a child, and these wishes may trigger longing. It is, however, crucial to note that longing for a baby is not identical to intending to have one. Many people have children without particularly longing to do so, while others may long for a(nother) child but decide against having it. Indeed, baby longing often appears when there are some external or internal obstacles that have led the individual to postpone or stop childbearing (Rotkirch 2007). Thus it may modify previous wishes and intentions relating to both the number and the timing of children: unlike general wishes, longing is a visceral emotion that calls for immediate action.

Third, the bottom right circle illustrates that baby longing can influence behaviour directly; through, for instance, the failure of an individual who is experiencing this longing to use contraception in intercourse, even though the individual has no conscious wish or intention to achieve pregnancy (see Miller's article in this issue for a further discussion of how desires may bypass intentions). Longing can also appear once the decision to try to have a child has been made and translated into proceptive behaviour (falling in love, having sexual intercourse, trying to achieve pregnancy or to adopt a child). And, finally, there is evidence that at least in women the experience of pregnancy, either interrupted or leading to birth, can cause baby longing (Rotkirch 2007).

In order to assess the importance of baby longing for contemporary fertility, we must understand whether longing modifies wishes and intentions, or whether it appears after the decision to have a child has been made and the individual is already engaged in proceptive behaviour. The latter case does not mean that baby longing is without demographic significance, since this feeling may sustain the attempt to have a child in the face of adversity, and it may also be important in preparing for parenthood.

\section{Questions, data and methods}

We study how baby longing correlates with reproductive motivation and behaviour as outlined above, paying special attention to its role in men's lives. We are also interested in how baby longing interacts with socio-economic and union factors known to influence fertility, and how this interaction varies by sex. While the cross-sectional data we use are not suited for analysing the causal effects or temporal precedence of baby longing in relation to other components of the TDIB scheme, the data can nevertheless provide a useful first assessment of the relative importance of longing as a fertility trait, fertility desire or as part of proceptive behaviour. 
Specifically, we address the following research questions:

How does baby longing vary in frequency and intensity between the sexes and with parity?

When was baby longing first experienced, to what extent is it reported to precede proceptive behaviour and what consequences is it reported to have for men and for women?

What socio-demographic characteristics are associated with men's longing for children?

The analyses use survey data from Finland, a country characterised by a high proportion of women in full-time employment and a high level of gender equity. Finland has comparatively high fertility ideals for a developed country - on average, both men and women in Finland would like to have 2.5 children (Miettinen and Rotkirch 2008, p.32). Finland also has one of the biggest gaps in Europe between desired and achieved fertility (Goldstein et al. 2003), mostly because of involuntary childlessness. Today, about thirty per cent of 45-year old women has three or more children, a higher proportion than in preceding post-war age cohorts. Men with higher socio-economic status are less likely to remain childless and are more likely to have several children. Among women, childlessness is most common among those with either very high or very low levels of education, while parities among mothers do not greatly vary by education (Statistics Finland 2010; Population Research Institute 2011).

Since the 1990s, young adult Finns have started using the term 'baby fever' (vauvakuume) to describe a strong longing for or fascination with babies. In order to measure the spread of this phenomenon, the nationally representative Family Barometer surveys of Väestöliitto, the Finnish Family Federation, have featured questions relating to baby fever since 2007. The surveys from 2007 and 2009 were sampled from the whole adult population, while a third survey from 2008 included only adults with no children or only one child. The data in this analysis is thus cross-sectional. The answers of consenting respondents from the 2008 survey will be linked to register information on births and marriages, allowing for a longitudinal follow-up in the future.

When asking about baby longing, we used both the common lay expression 'baby fever' in quotation marks, and the more neutral expression 'strong longing to have a child', since we anticipated that the use of 'baby fever' only might appear too feminine or frivolous for some respondents. The baby longing questions featured in slightly different contexts and places in each survey. The distributions by age, gender and parity to the baby longing question are consistent across the three surveys. Although we asked about 'strong longing', this article uses 'longing' and 'strong longing' interchangeably.

The Family Barometer 2007 is a representative survey of Finns aged 20-59 in 2007, N=1560, with a 52\% response rate (Paajanen 2007). Questionnaires were collected by regular mail, with two reminder letters sent to those who had not 
responded in the first rounds. The theme of the survey was family and kin relations, couple relations, fertility intentions and values relating to family life. Two questions were asked about baby fever: "Have you ever had a strong longing to have a child of your own ('baby fever')? No, never / Yes, a few times / Yes, several times"; and, for respondents who answered positively in the previous question, "What did the longing to have children lead to?", with eight response alternatives and the option to choose several of these alternatives: "I/my partner tried to become pregnant but we did not succeed"; "I/my partner became pregnant and we had our first child together"; "I/my partner became pregnant and we had the next child/children"; "I began the process of adopting a child"; "I did not have a child then because I did not have a suitable partner"; "I disagreed with my partner about childbearing and we divorced"; "No special change"; "Something else, please explain" (open question).

The Late Fertility Survey 2008 is a representative survey of adults who were aged 25-44 and had no children or one child in 2008, $\mathrm{N}=3058$, with a response rate of 44\% (Miettinen and Rotkirch 2008; Miettinen et al. 2011.) This survey is limited to low-parity respondents; however, due to postponement of parenting and high levels of childlessness, zero- and one-parity adults represent about $60 \%$ of women and $70 \%$ of men in this age cohort (aged 25-44) in Finland. Questionnaires were collected by regular mail with two reminder letters sent to those who had not responded in the first two rounds, and there was also an opportunity to answer a slightly shortened questionnaire online during the third round. This survey included detailed questions about childhood conditions, health, relationship history, work and family orientation, and current fertility intentions. Three questions were asked about baby longing: "Have you ever had a strong feeling that you would like to have a child of your own ('baby fever')? No I haven't; Yes, 1-2 times in my life; Yes, several times in my life"; respondents who gave a positive answer were asked, "Did you have a child as a result of that longing? Yes / No"; and "In what kind of life situation did that feeling first occurred?" with 11 options: "I have longed to have children since youth", "When I had fallen in love"; "When my friend had a child"; "When a relative had a child"; "When I or my partner tried to become pregnant"; "Following a pregnancy, imagined pregnancy, miscarriage or abortion"; "After having my first child"; "After having my second or subsequent children"; "In connection with a life crisis"; "At no special stage of life"; "In some other situation, please describe" (open response). The questionnaire is available at the English web page of Väestöliitto.

The Family Barometer 2009 is a representative survey of 20 to 59-year-old Finns at all parities in $2009, \mathrm{~N}=2000$, with a response rate of $64 \%$. The survey was conducted by TNS Gallup in October 2009 among respondents recruited through the Internet. The theme of the survey was family policy, family relations and social policy. If the respondent had at least one child less than 18 years old, $\mathrm{s} /$ he was asked about factors negatively and positively affecting the decision to 
have the last (youngest) child. Response alternatives for the positive reasons for having a child were randomly rotated and included baby longing: "What factors were especially important for you in connection with the birth of your last child? A longstanding wish to have a child(ren); For religious reasons I wish for as many children as God gives; I wanted a sister or brother for my older child/ren; My own strong longing to have a child, 'baby fever'; My partner's strong longing to have a child, 'baby fever'; I or my partner wished for the break in life provided by parental leave; I wanted a child since children were born in my close circle of friends and family; I did not especially plan to have a child; Something else, what?; Cannot say".

For illustrative purposes, we use excerpts from in-depth interviews from an ongoing study on women and men with three or more children in Finland. These were face-to-face, semi-structured interviews with respondents recruited through the snowball method. The interviews have been recorded, transcribed and analysed thematically. The questions include whether childbearing has involved experiences of baby fever. Male respondents were also asked whether they thought men can get baby fever. Thirty-two women and eight men were interviewed in 2010-11. Due to the ongoing nature of this study, we do not present a systematic analysis of this qualitative material.

The survey datasets were analysed with cross tabulations and multinomial and logistic regressions performed with STATA 11. The results section first analyses baby longing between men and women and in relation to parities in all three surveys (Q1). We then study sex differences in the situations in which baby fever first occurred, its triggers and outcomes using data from the Family Barometer 2007, and its role in helping couples decide when to have their last child using data from the Family Barometer 2009 (Q2). Finally, we build two regression models to analyse socio-demographic characteristics associated with men's and women's baby longing using data from the Late Fertility 2008 survey (Q3).

\section{Results}

\subsection{Prevalence, onset and perceived consequences of baby longing}

Do men feel a strong longing for children? Survey results show that many men do: nearly half of both men (44\%) and women (50\%) in the survey of adults of all parities in 2007 say they have longed to have a baby once or a few times in their lives. However, men's longing appears to be significantly less frequent and intense. Compared to women, men are twice as likely to report never having felt any baby longing, and are half as likely to have experienced this type of longing frequently ( $22 \%$ of women but $42 \%$ of men have never felt this longing, while 
$28 \%$ women and $13 \%$ of men have longed frequently, $\mathrm{p}<0.001$ for both associations).

For both sexes, longing is related to the number of children (Figure 2). Experiences of baby longing intensify first with the transition to parenthood, and later with the transition to higher parities. Childless individuals report having longed for babies less often than parents, while a higher proportion of parents with three or more children have more frequently felt this longing than other respondents. But baby longing is not equivalent to having children - even among parents with three or more children, one in three men and one in seven women report that they have never felt a strong longing to have a child. On the other hand, a substantial minority of the childless respondents say they had experienced frequent longing.

Figure 2:

Strong longing to have a child of one's own (baby fever) by sex and parity, 20 to 59year-old men $(n=532)$ and women $(n=877)$, Family Barometer 2007 of 20 to 59-yearold Finns
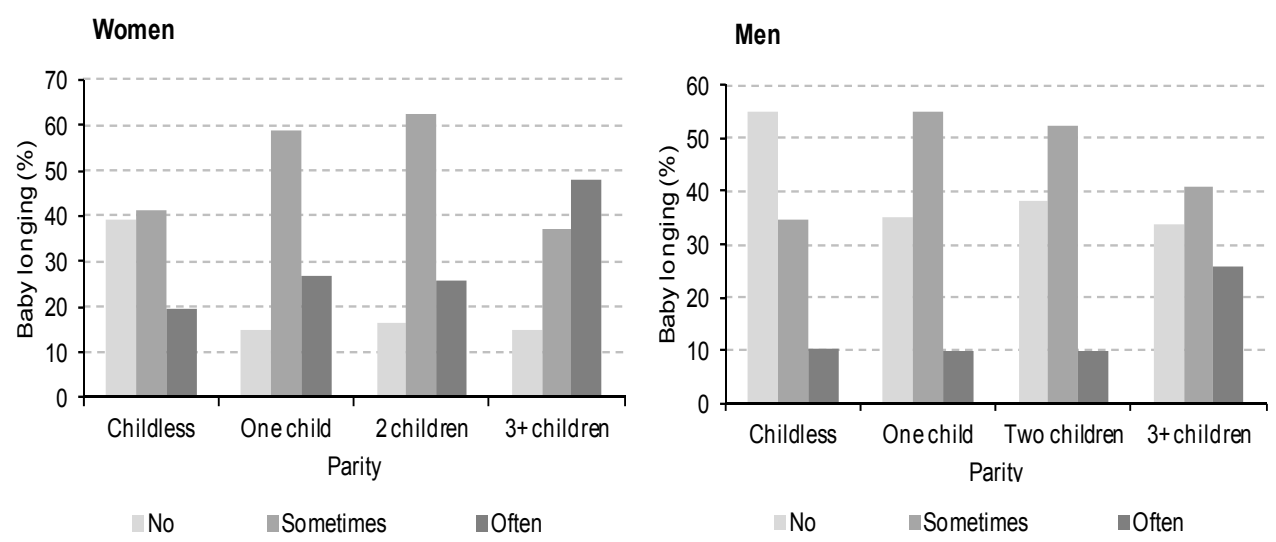

In in-depth interviews, fathers of three or more children were asked if they had felt baby fever, and whether they thought that men in general could feel it. While no one questioned the view that women can get baby fever, men's baby longing elicited more justifications and clarifications. Some respondents said they do not believe that men long for babies, at least not in the sense of 'fever'.

- No, I haven't had baby fever. Of my friends nobody has at least admitted to it so it must be women who have more baby fever, their biological clock ticks and those things. (Doctor, first child at age 32)

- No, I don't think men have it. It's a woman's disease. ... For men it takes longer to grasp that a baby is on its way. I had it a bit while we waited for it to be born, a kind of anticipation. But not so that I would have begged my wife 'let's make a baby', like women may do. (Engineer, first child at age 25) 
These two fathers had not strongly longed for babies, although they had several children already. They thought there were sex differences related to the intensity of the longing, and reflected on how women have "more" baby longing, comparing their own anticipation to women's "begging". For these respondents, the expression baby fever refers to such an intense longing that they excluded themselves from it. Other fathers, however, thought that baby fever was a suitable term for describing their own experience or that of friends.

- Yes, I've had it. It can also give you sexual kicks, the thought that you are conceiving... You may get those periods in life when you feel drawn to other people's babies because it appears to fulfil some kind of need. You can say that it's baby fever. ... If men get some joy from children at all, which they clearly do once in a while, it's clear that they can also long for them. (IT consultant, first child at age 21)

- Yes, I think they do. The symptoms... they are more difficult to define, but I'd say they do. I must have had it but it was quite mild, maybe just over 37 centigrade, a slight temperature. (Musician, first child at age 33)

The IT consultant quoted above said he thinks that since men can enjoy children, they may also long for such pleasures; he also reported that baby fever fed into his sexual excitement and a general interest in infants. The second quotation jokingly describes men's baby fever as only a mild temperature. Taken together, the views expressed in these latter excerpts are in line with the overall survey results: men do feel baby longing, but typically it is more rare and milder than women's longing.

When did the strong longing for a child occur for the first time? This question was asked in the Late Fertility survey with zero- and one-parity adults in 2008.

The most common situation in which both men and women reported having first longed for a baby was, as Figure 3 shows, when the couple was trying to conceive. Presumably, for these respondents the wish, intention and attempt to have a child had preceded longing. In in-depth interviews, one father described this kind of situation:

- Did you experience baby fever before having your first child?

- Not really since I wasn't really... I led a nice bachelor's life until then.

- So when did you get baby fever?

- When she was pregnant.

- How would you describe it?

- You couldn't really think of anything else! (Scholar, first child at age 43)

This quotation shows how baby longing can appear during pregnancy and mix with the anticipation of becoming a father. For the other response alternatives shown in Figure 3, longing can be interpreted as mainly preceding attempts at conception. Our data do not allow for unequivocal distinctions in this regard: for 
instance, one can already be trying to have a child, but start to actually yearn for it only after seeing a sibling's baby. Nevertheless, we can make a rough judgement that longing preceded proceptive behaviour for the majority of respondents who reported having ever longed for babies.

\section{Figure 3:}

When did you first experience a strong longing for a child ('baby fever')? Respondents who report having longed for a child, men $(\mathrm{N}=514)$ and women ( $N=1001$ ), Late Fertility survey of 25 to 44-year old Finns with 0 or 1 child in 2008, in per cent

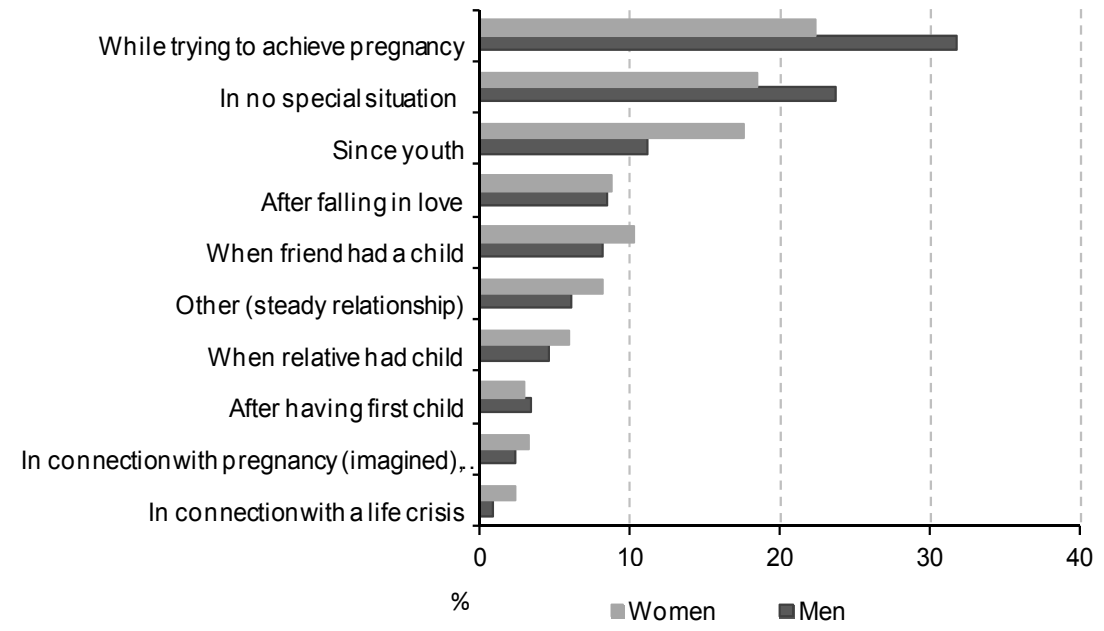

For both men and women, the second largest group consists of individuals reporting baby longing without any particular triggering situation (Figure 3). Since the response alternatives featured an open question, this answer should not tap into a lack of suitable alternatives, but should genuinely reflect those who could not detect or remember specific triggers.

The third largest group, again among both sexes, consists of respondents who said they have felt baby longing since youth. Interestingly, more than one in ten men chose this option, indicating that men's baby longing may also significantly precede the actual attempt to have a child. Early onset was, however, more common among women. Women also more often reported situations relating to social learning and imitation, such as childbearing among friends and relatives. Interestingly, men and women do not appear to differ in longing triggered by childbirth, abortion and miscarriage, although these events directly affect only female physiology.

The response alternative "other, please explain" was chosen by seven per cent, of whom the majority wrote that they were living in a stable couple relationship when they first felt the desire to have a child. It is likely that among respondents answering "in no particular situation", many would have been living 
in similar circumstances - that is, in a stable relationship with no special events affecting fertility motivation, but no tangible childbearing plans either - when they first felt a longing for a child.

We conclude this section by studying how baby longing was reported to relate to childbearing outcomes in two surveys. First, in the 2007 survey of all-parity adults, we asked about the consequences of longing for those having ever experienced it, allowing for multiple responses. As Figure 4 shows, most respondents said baby longing resulted in having one or several children. Among both sexes, one in four said baby longing led to having a first child. (Half of these respondents had only one child, but half of them had two children or more and reported feeling baby longing only for the first child.) One in ten respondents said baby longing resulted in second or subsequent children, but not the first child; while every third man and almost every second woman said baby longing had preceded both their first and subsequent children. The positive relationship between frequent longing and higher parities shown in Figure 1 above was thus corroborated in these self-reported consequences.

\section{Figure 4:}

Reported consequences of baby longing, 20 to 59-year-old Finnish men $(\mathrm{N}=307)$ and women $(\mathrm{N}=689)$ in 2007 who report having had baby longing, in per cent; percentages exceed 100 since multiple options were allowed

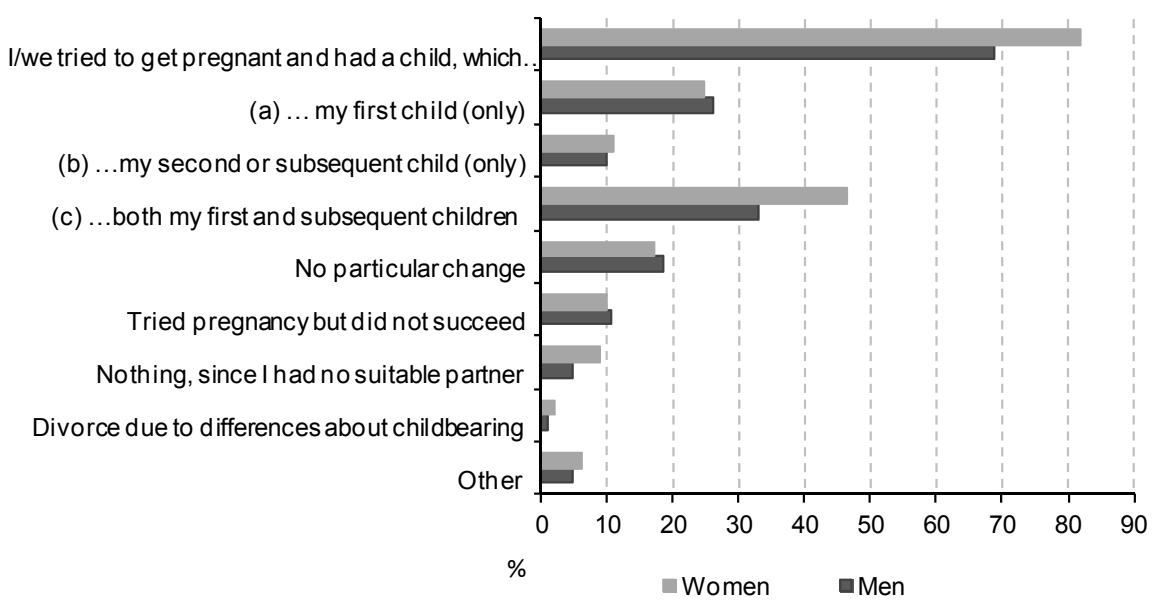

Baby longing does not necessarily lead to having a child. One in six respondents reported no particular change, and about $10 \%$ had tried to have a child without success. A higher proportion of women compared to men said that longing did not result in a child due to the lack of a suitable partner. The option "I tried to adopt a child" was chosen by only three respondents and is not included here. Only a few per cent reported having divorced their partner due to differences in childbearing desires. 
While divorce was a rare outcome in the survey, it was spontaneously referred to in some in-depth interviews. In the following excerpt, a father recounted how his acquaintances might have been divorced if they had not succeeded in having children.

- Baby fever may be so strong, that if the problem with childlessness is not been solved - one couple I know, there would have been a change of mates, I mean that maybe that relationship wouldn't have lasted, because the man wanted a child and a family and it was self-evident that he should have them. Of course there were the possibilities of adoption and other things but it was a real stress in that relationship before the kids started appearing. ... It must be this gender equality, that men have also started having baby fever. (IT consultant, first child at age 21).

In all, women and men report similar behavioural outcomes of baby longing, although longing among men appears to occur less often in a context without a suitable partner, and is also less often connected to all his children.

Second, we asked parents which factors contributed to the decision to have the last child in the survey of all parities in 2009 (Figure 5). For men, the most popular reason was "to continue the lineage", followed by a long-standing wish to have a child and wanting a sibling for an existing child. Thus, men's baby longing featured as a second-order factor - it was not the most salient reason, but it was not among the least prominent factors either. Men also reported that their partner's baby longing had affected having their last child about twice as often as their own longing had. The other answers relating to friends, religion, kin and work were selected by only a few men.

Women's own baby fever was the third most frequent factor, after a long-time wish for children and the wish for a sibling, with a significant difference compared to men $(\mathrm{OR}=4.42, \mathrm{p}=0.00)$. Men also reported partner's baby fever as an influential factor more often than women did, and this difference came close to being statistically significance $(\mathrm{OR}=1.56, \mathrm{p}=0.07)$ (Figure 5).

There were also gender differences in baby longing when we distinguished respondents by parity.

As Figure 6 shows, fathers with one child mentioned their own and their partner's baby longing as an important factor just as often. For all other parities, both men and women reported the woman's baby longing as a decisive factor more frequently than the man's. Sex significantly predicted own baby longing for the parents of one (OR $0.20, \mathrm{p}=0.00)$, two $(0.32, \mathrm{p}=0.007)$ and three or more children $(\mathrm{OR}=0.07, \mathrm{p}=0.01)$.

An extreme version of differing emotions within the couple was provided in the in-depth interview with one father, whose second child was wanted by his wife, while he was more neutral, and whose third child came about without his knowledge. 
- My partner wanted it and I wasn't very keen, and then suddenly she was pregnant. I believe it was planned, I believe she knew, although I didn't know anything. (Scholar, first child at 43)

\section{Figure 5:}

Which goals were especially important for you in connection with the birth of your last child? 20 to 59-year-old Finns in 2009, men $(\mathrm{N}=305)$ and women $(\mathrm{N}=263)$ by number of children under age 18 , in per cent

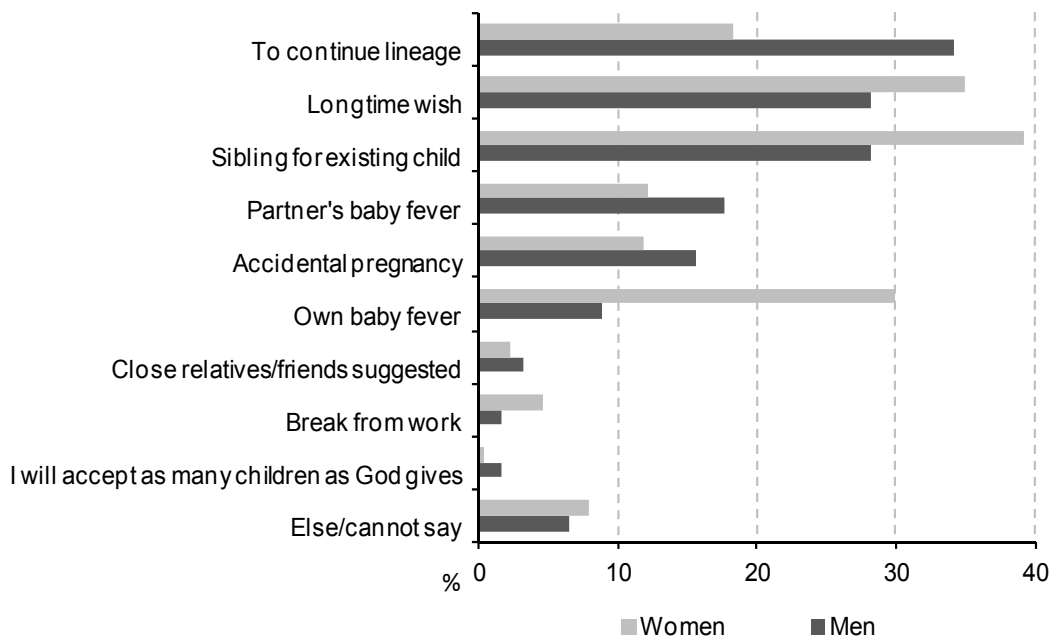

Figure 6:

Own or partner's baby longing contributed to decision to have last child, 20 to 59year-old Finns in 2009, men $(\mathrm{N}=305)$ and women $(\mathrm{N}=263)$ by number of children under age 18, in per cent

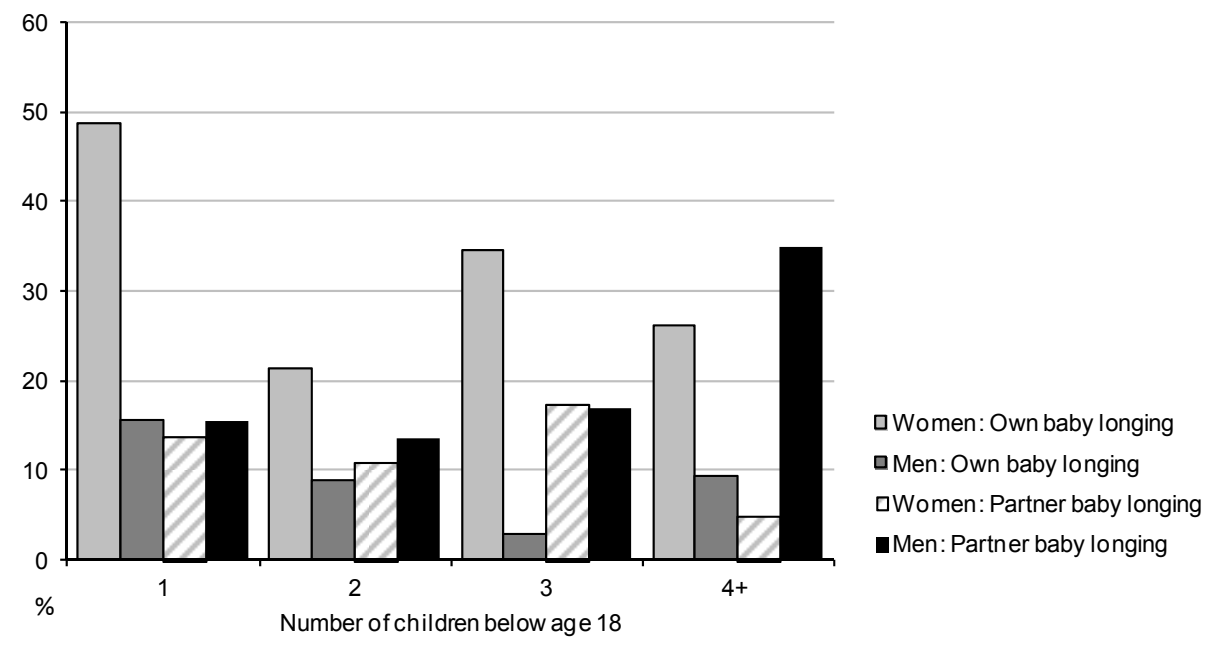


In sum, results from three different Finnish surveys indicate a notable overlap between men's and women's experiences of longing for a child of one's own. At the same time, men long less often for babies, their longing leads to a child less often than for women, and men typically long in connection with the transition to fatherhood, but not higher parities.

\subsection{Socio-demographic determinants of men's longing}

We have detected both similarities and differences in baby longing between the sexes. Next we study which men are more likely to long for children. We used logistic regression to analyse this question with the Late Fertility survey of zeroand one-parity adults from 2008. These data include a large number of respondents and detailed information on partnership history and fertility intentions, although the survey obviously does not represent the one-third of 25 to 44-year-old Finns who have two or more children.

The predicted variable was ever having experienced baby longing ("no" versus "yes, a few times" or "yes, frequently"). We include socio-demographic variables known to affect men's fertility as well as other variables which had or came close to having statistical significance in univariate analysis ( $p$-values less than 0.25 ) after controlling for age. Baby longing is also very strongly associated with experiences of infertility or of having ever tried more than 12 months to achieve pregnancy without success, but this variable was excluded as tautological.

Univariate regressions indicate that both union and fertility history relate to baby longing (Table 1). Type of union, numbers of lifetime unions and having a spouse who wants a child all increase the likelihood of baby longing, as does already being a parent and intending to have a child. Union variables yield higher odds ratios for men than for women, while the reverse is true for fertility variables.

As predicted by previous research, higher socio-economic status was shown to be related to having a child among men in these data as well. In logistic regressions controlling for age, the odds ratios (OR) for having a child (parity one versus zero) were significantly stronger among men with higher income (when lower income is the reference, odds ratios were $\mathrm{OR}=2.2$ for middle income and $\mathrm{OR}=3.4$ for highest income, $\mathrm{p}=.000)$ and higher status occupation $(\mathrm{OR}=1.28$, $\mathrm{p}=.000$ ); there was no interaction between baby fever and income or education when predicting numbers of children. Both income and occupation were also significantly associated with lower numbers of children for women $(0.64$ for income and 0.87 for occupation, $\mathrm{p}<0.005$ for both, not shown in tables). In univariate regressions, occupation showed a positive effect, so that white collar men were most likely to have longed for a child, and men with a low income showed a tendency to have longed less often (Table 1). Interestingly, neither education nor income was significantly related to baby longing in men. Since the lack of association between income and parities could stem from the limitation of 
our data to low-parity adults, we repeated this analysis for income and education with the all-parity survey from 2007, with similar results (not shown here).

Table 1:

Study variables and their univariate associations with baby longing $(0=\mathrm{No}, 1=$ Yes $)$ controlling for age, Finnish 0- and 1-parity men $(\mathrm{N}=779)$ and women $\mathrm{N}(1202)$ in 2008, in per cent, odds ratios

\begin{tabular}{|c|c|c|c|c|c|}
\hline \multirow[t]{2}{*}{ Variable } & & \multicolumn{2}{|c|}{ Men } & \multicolumn{2}{|c|}{ Women } \\
\hline & & $\%$ & OR & $\%$ & OR \\
\hline \multirow[t]{2}{*}{ Baby longing } & No & 45.2 & & 29.6 & \\
\hline & Yes, a few times or often & 54.8 & & 70.3 & \\
\hline \multirow[t]{2}{*}{ Age } & $25-34$ & 59.6 & 1.00 (ref) & 62.6 & 1.00 (ref) \\
\hline & $35-44$ & 40.4 & 0.88 & 37.4 & $0.61 * * *$ \\
\hline \multirow[t]{2}{*}{ Parity } & 0 & 45.1 & 1.00 (ref) & 47.9 & 1.00 (ref) \\
\hline & 1 & 54.9 & $2.91 * * *$ & 52.1 & $3.93 * * *$ \\
\hline \multirow[t]{3}{*}{ Education } & Vocational or less & 42.3 & 1.09 & 27.3 & 0.98 \\
\hline & Vocational or voc. colleges & 30.6 & 1.00 (ref) & 41.2 & 1.00 (ref) \\
\hline & University & 27.1 & 1.07 & 31.4 & 0.81 \\
\hline \multirow[t]{3}{*}{$\begin{array}{l}\text { Income } \\
\text { (men/women) }\end{array}$} & $\begin{array}{l}\text { Under } 1300 / 1200 € \text { per } \\
\text { month }\end{array}$ & 15.5 & $0.67+$ & 26.9 & 0.89 \\
\hline & $\begin{array}{l}1300 / 1200-2200 / 1900 € \text { per } \\
\text { month }\end{array}$ & 53.8 & 1.00 (ref) & 49.9 & 1.00 (ref) \\
\hline & $2200 / 1900+€$ per month & 30.6 & 1.02 & 23.2 & 0.95 \\
\hline \multirow[t]{4}{*}{ Occupation } & $\begin{array}{l}\text { Entrepreneur, farmer or } \\
\text { other }\end{array}$ & 17.6 & 1.00 (ref) & 23.8 & 1.00 (ref) \\
\hline & Blue-collar & 41.2 & 1.25 & 39.6 & 1.08 \\
\hline & Lower white-c & 12.3 & 0.60 & 17.2 & 0.99 \\
\hline & Upper white-c & 28.9 & $2.58 *$ & 19.4 & 1.03 \\
\hline \multirow[t]{3}{*}{ Current union } & None or dating & 25.6 & 1.00 (ref) & 28.7 & 1.00 (ref) \\
\hline & Cohabitation & 32.2 & $2.58 * * *$ & 33.8 & $1.83 * * *$ \\
\hline & Marriage & 42.2 & $4.37 * * *$ & 37.5 & $3.21 * * *$ \\
\hline \multirow{2}{*}{$\begin{array}{l}\text { Number of } \\
\text { lifetime unions }\end{array}$} & $0-1$ & 59.1 & 1.00 (ref) & 53.2 & 1.00 (ref) \\
\hline & $2+$ & 40.9 & $2.61 * * *$ & 46.8 & $1.64 * * *$ \\
\hline \multirow{2}{*}{$\begin{array}{l}\text { Length of current } \\
\text { union }\end{array}$} & $0-5$ years & 45.2 & 1.00 (ref) & 47.1 & 1.00 (ref) \\
\hline & $6+$ years & 54.8 & 1.26 & 52.9 & 1.10 \\
\hline \multirow{4}{*}{$\begin{array}{l}\text { Intends to have } \\
\text { a(nother) child }\end{array}$} & No & 23.2 & $0.39 * * *$ & 25.4 & $0.69 *$ \\
\hline & Cannot say & 19.4 & 1.00 (ref) & 18.0 & 1.00 (ref) \\
\hline & Yes, maybe & 36.2 & $2.05 * *$ & 36.2 & $3.11 * * *$ \\
\hline & $\begin{array}{l}\text { Tries/partner tries } \\
\text { pregnancy or is pregnant }\end{array}$ & 21.3 & $5.94 * * *$ & 20.4 & $9.11 * * *$ \\
\hline \multirow{2}{*}{$\begin{array}{l}\text { Spouse wants } \\
\text { a(nother) child }\end{array}$} & No and cannot say & 21.4 & 1.00 (ref) & 21.9 & 1.00 (ref) \\
\hline & Yes & 78.6 & $3.37 * * *$ & 78.1 & $2.13 * * *$ \\
\hline \multirow{2}{*}{$\begin{array}{l}\text { Intended number } \\
\text { of children }\end{array}$} & 0,1 or cannot say & 42.5 & 1.00 (ref) & 47.4 & 1.00 (ref) \\
\hline & $2+$ & 57.5 & $2.73^{* * *}$ & 52.6 & $3.97 * * *$ \\
\hline \multirow{2}{*}{$\begin{array}{l}\text { Religion is } \\
\text { important in life }\end{array}$} & No, not very, somewhat & 93.9 & 1.00 (ref) & 91.2 & 1.00 (ref) \\
\hline & Very important & 6.1 & 1.54 & 8.9 & 0.97 \\
\hline \multirow{2}{*}{$\begin{array}{l}\text { Number of } \\
\text { siblings }\end{array}$} & $0-1$ & 51.3 & 1.00 (ref) & 50.1 & 1.00 (ref) \\
\hline & $2+$ & 48.7 & $1.29+$ & 49.9 & 1.17 \\
\hline
\end{tabular}

Note: $* * * p<0.001, * * \mathrm{p}<0.01, * \mathrm{p}<0.05,+\mathrm{p}<0.10$ 
Next, we analysed the significant univariate associations with two multivariate regression models. The first of these models studied the relationships of socio-demographic characteristics (age, parity and marital status, education, income and occupation) with baby longing. Income and occupation again proved to be statistically insignificant for men after controlling for age, parity and marital status; and they were excluded from the model in order to retain a higher sample size. Therefore, the final first model includes age, parity and marital status, controlling for education. The second regression model further adds the two variables, which remained significant after controlling for parity and marital status, as well as for fertility intentions and number of lifetime unions. The regression models were conducted separately for men and women and tested for sex interaction effects (Table 2.)

Table 2:

Multivariate logistic regression models predicting ever strongly longing for a child, Finnish men $(\mathrm{N}=779)$ and women $(\mathrm{N}=1202)$ of parity 0 and 1 in 2008, odds ratios (standard errors), controlling for education

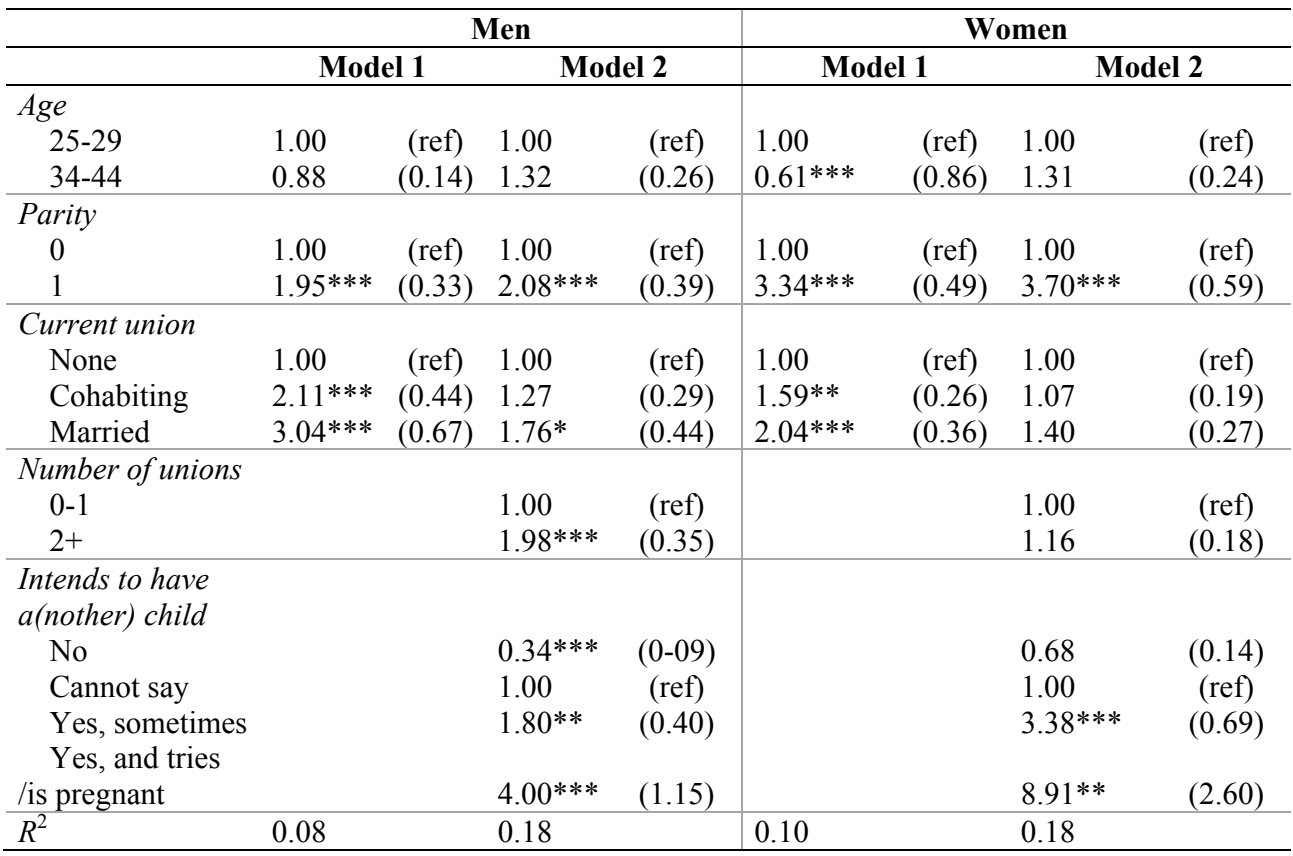

Note: $* * * \mathrm{p}<0.001, * * \mathrm{p}<0.01, * \mathrm{p}<0.05,+\mathrm{p}<0.10$. Only variables with significant associations with baby longing in univariate analysis were included in the multivariate models (see Table 1).

In the first model, being a father or mother of a child and cohabiting or being married raised the odds ratio for having ever felt baby longing. When controlling for the number of unions and fertility intentions, the impact of union type on baby 
longing is shown to be much smaller, and it retains its statistical significance only for married men.

In the second model, the effects of parity are slightly more pronounced. Having had several unions raises the odd ratios for baby longing significantly in men. Model 2 indicates that union-related variables relate more to longing among men, while age- and fertility-related variables are associated with a higher likelihood of baby longing among women. Sex differences are statistically significant for the associations of number of unions $(\mathrm{p}=0.01)$, but not for age and intentions $(p=0.06$ and $p=0.08$, respectively) or for marital status $(p=0.23)$ and parity $(\mathrm{p}=0.17)$.

\section{Conclusions}

Popular perceptions reported in the media and interviews portray baby longing as either an exclusively female emotion, or as a feeling men have not been accustomed to talking about. This study is the first to explore the social and situational characteristics of men's baby longing, and to compare them with similar results for women. Results show that almost every second Finnish man has experienced a strong longing for a child. Baby longing appears to be distributed in two overlapping curves, so that a higher proportion of men have never longed, while a higher proportion of women have longed frequently. These results are in line with other research on parenting emotions, which show both gender differences and similarities (Basten 2009). A recent study of baby fever in the UK and the US found gender distributions of baby fever very similar to those shown in our results (Brase and Brase 2011). Gender and baby longing is a question of degrees, not of exclusive categories. As one father we interviewed put it, men may experience a slight rise of temperature" if not full-blown "baby fever". The question of whether only women experience the most physically intense forms of baby longing, and the possible hormonal underpinnings of such a sex difference, is interesting and merits further research.

For both sexes, longing is typically involved in the transition to the first child, and to a lesser degree with having higher than average numbers of children, which in Finland means three or more children. That a sizeable minority of respondents, including parents with many children, say they have never strongly longed to have a child serves as a reminder that baby longing is not a universally occurring emotion, comparable to romantic or parental love.

Baby longing figures at different stages of the Traits-Desires-IntentionsBehaviour scheme of reproductive behaviour (Miller 1992). For a small minority of men, it appears in youth, presumably as a part of the basic personality traits that eventually shape the childbearing desires of the adult individual. Most typical is for baby longing to play into childbearing desires preceding attempts to achieve pregnancy. Finally, for about every third man who reported having longed for a 
child, the longing emerged during proceptive behaviour, after the decision to try to have a child had been taken.

Men and women reported first feeling baby longing in similar situations. A man's longing was more often triggered by trying to have a baby with his partner or in no particular situation, while a woman was more likely to say she had felt it since youth. Men's baby longing was reported to result in having a child slightly less often than women's longing did. Both sexes also reported the man's baby longing had less influence on childbearing decisions, especially in relation to second or higher parities. In line with several other studies of childbearing in developed societies, we find that the woman in a heterosexual couple is perceived as having a bigger 'say' on childbearing intentions and the decisions of both spouses. For instance, a recent study on childless Canadian men found that they rated their partner's interest in or desire for having children as a more influential factor than their own interest and desire (Roberts et al. 2011). The similarity in fertility ideals and intentions within a couple, which has frequently been found (e.g. Thomson 1997), may thus often be preceded by sex differences in the intensity of longing that shapes ideals and intentions (see Miller et al. 2004).

Interestingly, male baby longing was not predicted by standard socioeconomic variables, such as age and levels of income and education. Men's income, occupational status and baby longing were all positively associated with having a child compared to being childless in our data. However, there appear to be separate pathways through which material resources and baby longing affect men's fertility. Similar results have been reported in Canada, where sociodemographic factors were shown to predict men's childbearing desires only weakly (Roberts et al. 2011). Some observers have speculated that male longing is a new discursive phenomenon, perhaps resulting from increasing gender equality (as one father quoted above has suggested), and that a cultural 'taboo' against men talking about children prevents men from expressing their feelings (Mills 2010). If this is true, men with higher education would be expected to be less conformist and more eager to express 'feminine' views. This interpretation was not supported by our results. Rather, it seems that income promotes union formation and childbearing intentions, which in turn may trigger baby longing for the minority of men who experience it.

The negligible association of baby longing with socio-economic status may be specific to Finland, Canada or other countries with widespread reproductive rights, relatively low levels of social inequality and high levels of gender equality. Family-friendly policies reduce the costs of childbearing in Finland relative to many other countries, and the numbers of children are relatively evenly distributed among mothers from different social classes. It would be interesting to see how baby longing interacts with gender and social class in other, less egalitarian settings.

Our findings show that baby longing among men is particularly influenced by relationship history. Not only is being in a union correlated with having longed to 
have a child, but men who have been in several unions tend to have experienced the desire to have a baby more often. Having been in several relationships also increases the likelihood of having many children for men, but not for women, at least in the US (Jokela et al. 2010). Baby longing may therefore be one of the emotional pathways through which men with many unions end up having more children. An alternative explanation would be that men with several unions are, from the start of their reproductive careers, more family-oriented than other men.

Women's baby longing showed stronger associations with fertility history and intentions than with partnership status. For both sexes, baby longing did not significantly increase with age, and in one model it decreased with age for women. In line with the results from comparable studies (Roberts et al. 2011; Brase and Brase 2011), we find that the 'biological clock' does not increase in power until the end of an individual's fertile years, but tends to taper off after the mid-thirties. Unlike Brase and Brase (2011), however, we did not find evidence for men's baby longing starting and continuing later in the lifespan than for women.

This study used only cross-sectional survey data, which give little indication of causality, and the survey from 2008 is limited to low-parity respondents. We will collect follow-up data from the 2008 sample in the future in order to examine in more detail the temporal order between baby longing and covariates, and include respondents who go on to have two or more children. Another limitation of the current study is that demographic survey data is less than ideal for studying emotions: we do not know how respondents interpret the formulations of the response alternatives, and they are occasionally required to remember distant events. We hope to overcome some of these limitations when the collection of in-depth interviews is completed.

We conclude that, while male baby longing may guide fertility behaviour even before couple formation, it appears to be especially important for sustaining fertility intentions and preparing for fatherhood. The ultimate roots of the emotions involved in baby longing merit further study, as do their proximate triggers, the interaction of baby longing with fertility desires and intentions, and the impact of baby longing on contemporary couple negotiations and childbearing behaviour.

\section{Acknowledgements}

The authors wish to thank Anneli Miettinen, Pirjo Paajanen and Lassi Lainiala for their help with the surveys. We are also grateful to Anna Michin, Támas DávidBarrett and Mikko Myrskylä for their helpful suggestions, and to three anonymous referees and the editors for their detailed and constructive comments on earlier drafts of this manuscript. The research received financial support from 
the Kone Foundation, the Finnish Family Federation Väestöliitto and research funds of the University of Helsinki.

\section{References}

Basten, S. 2009. Neuroscience and parental behaviour. The Future of Human Reproduction Working Papers 2. http://www.sjc.ox.ac.uk/3152/WP44\%20Neuroscience\%20and\%20parental\%20behav iour.pdf.download

Berrington, A. 2004. Perpetual postponers? Women's, men's and couple's fertility intentions and subsequent fertility behaviour. Population Trends 117: 9-19.

Bonke, J. and G. Esping-Andersen 2009. Family investments in children - productivities, preferences, and parental child care. European Sociological Review 27(1): 33-55.

Booth, A. and A. Crouter (eds.) 1998. Men in families. When do they get involved? What difference does it make? Mahwah, NJ: Erlbaum.

confessionsofameanmommy.com 2009. Baby lust and how it clashes with mean mommyhood. http://www.confessionsofameanmommy.com/baby-lust-and-how-itclashes-with-mean-mommyhood

Brase, G.L. and S.L. Brase 2011. Emotional regulation of fertility decision making: What is the nature and structure of 'baby fever'? Emotion, advance online publication 15.8.

de Bruijn, B.J. 1999. Foundations of demographic theory. Choice, process, context. Amsterdam: Thela thesis.

Fernandez-Duque, E., C.R. Valeggia, and S.P. Mendoza 2009. The biology of paternal care in human and nonhuman primates. Annual Review of Anthropology 38: 115-130.

Fleming, A.S., C. Corter, J. Stallings and M. Steiner 2002. Testosterone and prolactin are associated with emotional responses to infant cries in new fathers. Hormones and Behavior 42: 399-413.

Forste, R. 2002. Where are all the men?: A conceptual analysis of the role of men in family formation. Journal of Family Issues 23(5): 579-600.

Goldstein, J., W. Lutz and M.R. Testa 2003. The emergence of sub-replacement family size ideals in Europe. Population Research and Policy Review 22(5-6): 479-496.

Gordon, I., O. Zagoory-Sharon, J.F. Leckman and R. Feldman 2010a. Oxytocin and the development of parenting in humans. Biol Psychiatry 68:377-382.

Gordon, I., O. Zagoory-Sharon, J.F. Leckman and R. Feldman 2010b. Prolactin, oxytocin, and the development of paternal behavior across the first six months of fatherhood. Hormones and Behavior 58: 513-518.

Henwood, K. 2009. On delayed fatherhood: The social and subjective 'logics' at work in men's lives (a UK Study). In The Future of Motherhood in Western Societies, ed. Beets, G., Schippers, J. and te Velde, 155-175. EAmsterdam: Springer.

Hopcroft, R.L. 2006. Sex, status, and reproductive success in the contemporary United States. Evolution and Human Behavior 27(2): 104-120.

Jamieson, L., K. B. Milburn, R. Simpson and F. Wasoff 2010. Fertility and social change: The neglected contribution of men's approaches to becoming partners and parents. The Sociological Review 58: 463-485.

Jokela, M., A. Rotkirch, I.J. Rickard, J. Pettay and V. Lummaa 2010. Serial monogamy increases reproductive success in men but not in women. Behavioral Ecology 21: 
906-912.

Kaplan, H., J. Lancaster and K. G. Anderson 1998. Human parental investment and fertility: the life histories of men in Albuquerque. In Men in families. When do they get involved? What difference does it make?, ed. A. Booth and A. Crouter, 55-109. Mahwah, NJ: Erlbaum.

Kravdal, Ø. and R.R. Rindfuss 2008. Changing relationships between education and fertility: a study of women and men born 1940 to 1964 . American Sociological Review 5: 854-873.

Lamb, M.E. 2010. The role of the father in child development. New Jersey: John Wiley \& Sons.

Maestripieri, D. 1999. The biology of human parenting: Insights from nonhuman primates. Neuroscience \& Biobehavioral Reviews 23: 411-422.

Maestripieri, D. 2011. Emotions, stress, and maternal motivation in primates. American Journal of Primatology 73:516-529.

Maestripieri, D., J.R. Roney, N. De Bias, K.M. Durante and G.M. Spaepen 2004. Father absence, menarche and interest in infants among adolescent girls. Developmental Science 7(5): 560-566.

Miettinen, A. and A. Rotkirch 2008. Milloin on lapsen aika. Lastenhankinnan aikeet ja esteet [When is the right time for children? Fertility intentions and barriers]. Family barometer 2008. E34. Helsinki: Population Research Institute, Väestöliitto.

Miettinen, A., A. Rotkirch and S. Basten 2011. Gender equity and fertility revisited. Evidence from Finland. Demographic Research 24(20): 469-496.

Miller, W.B. 1986. Proception: an important fertility behavior. Demography 23: 579-94.

Miller, W.B. 1992. Personality traits and developmental experiences as antecedents of childbearing motivation. Demography 29: 265-85.

Miller, W.B. 2001. The ontogeny of human bonding systems: Evolutionary origins, neural bases, and psychological manifestations. Boston: Kluwer.

Miller, W.B. 2011. Differences between fertility desires and intentions: implications for theory, research and policy. Vienna Yearbook of Population Research Vol.9: 75-98.

Miller, W.B., D.E. Bard, D.J. Pasta and J.L. Rodgers 2010. Biodemographic modeling of the links between fertility motivation and fertility outcomes in the NLSY79. Demography 47(2): 393-414.

Miller, W.B. and D.J. Pasta 1995. Behavioral intentions: which ones predict fertility behavior in married couples? Journal of Applied Social Psychology 25: 530-555.

Miller, W.B., L. Severy and D.J. Pasta 2004. A framework for modelling fertility motivation in couples. Population Studies 58(2): 193-205.

Mills, D. 2010. Why can't men be broody too? Women aren't the only ones with biological clocks. The difference is that they can talk about it. The Daily Mail 27.9.2010. http://www.dailymail.co.uk/femail/article-1315456/Women-arent-onesbiological-clocks-says-wannabe-dad.html

Nettle, D. 2008. Why do some dads get more involved than others? Evidence from a large British cohort. Evolution and Human Behavior 29: 416-23.

Nettle, D. 2011. Flexibility in reproductive timing in humans: integrating ultimate and proximate explanations. Philosophical Transactions of the Royal Society, B366: 357365.

Nettle, D. and T.V. Pollet 2008. Natural selection on male wealth in humans. The American Naturalist 172(5): 658-66. 
Paajanen, Pirjo 2007. Mikä on minun perheeni? - Suomalaisten käsityksiä perheestä vuosilta 2007 ja 1997. [Who belongs to my family? Finns family perceptions in 2007 and 1997.] Family barometer 2007, E 30. Helsinki: Population Research Institute, Väestöliitto.

Pikul, C. 2011. The clockwatcher. How do you know when - or if - you should have a baby? American ELLE magazine February: 164-166.

Population Research Institute 2011. Facts and figures: fertility in Finland. http://www.vaestoliitto.fi/in_english/population_research_institute/facts-andfigures/fertility-in-finland

Puur, A., L.Sz. Oláh, M. I. Tazi-Preve and J. Dorbritz 2008. Men's childbearing desires and views of the male role in Europe at the dawn of the 21st century. Demographic Research 19: 1883-1912.

Roberts, E., A. Metcalfe, M. Jack and S.C. Tough 2011 Factors that influence the childbearing intentions of Canadian men. Human Reproduction 26(5):1202-1208.

Rotkirch, A. 2007. 'All that she wants is another baby?' Longing for children as a fertility incentive of growing importance. Journal of Evolutionary Psychology 5(1-4): 89-104.

Rotkirch, A. 2008. What is 'baby fever'? Contrasting evolutionary explanations of proceptive behavior. In The new evolutionary social science. Human nature, social behaviour and social change, ed. Meleghy, T., Meyer, P. and Niedenzu, H-J., Boulder, 147-158. CO: Paradigm Publishers.

Silk, J.B. 2003. Natal attraction in adult female baboons (Papio cynocephalus ursinus) in the Moremi reserve, Botswana. Ethology 109(8): 627-644.

Statistics Finland 2010. Vital statistics 2008. Helsinki: Statistics Finland.

Thomson, E. 1997. Couple childbearing desires, intentions, and births. Demography 34(3): 343-354.

Thomson, E. and J.M. Hoem 1998. Couple childbearing plans and births in Sweden. Demography 35(3): 315-322.

Thomson, E., E. McDonald and L.L. Bumpass 1990. Fertility desires and fertility: hers, his, theirs. Demography 27(4): 579-588.

Trivers, R.L. 1972. Parental investment and sexual selection. In Sexual selection and the descent of man 1871-1971, ed. Campbell, B., .136-179. Chicago: Aldine.

Von der Lippe, H. 2010. Motivation and selection processes in a biographical transition: a psychological mixed methods study on the transition into fatherhood. Journal of Mixed Methods Research 4(3): 199-211. 